\title{
Early stress by repeated maternal separation induces long-term neuroinflammatory response in glial cells of male rats
}

\author{
María Banqueriab*, Marta Méndez ${ }^{\mathrm{ab}}$, Eneritz Gómez-Lázaro ${ }^{\mathrm{c}}$, Jorge L. \\ $\operatorname{Arias}^{\mathrm{ab}}$ \\ ${ }^{a}$ Laboratory of Neuroscience, Department of Psychology. University of Oviedo, Plaza Feijoo, s/n, E-33003, Oviedo, \\ Spain. \\ BInstituto de Neurociencias del Principado de Asturias (INEUROPA) \\ ${ }^{\mathrm{c}}$ Department of Basic Psychological Processes and their Development, Basque Country University, Avda, Tolosa 70, \\ 20018 San Sebastian, Spain.
}

Running title: MS induces long-term glial response 


\title{
Early stress by repeated maternal separation induces long-term neuroinflammatory response in glial cells of male rats
}

\begin{abstract}
Childhood maltreatment and neglect leads to a wide range of mental disorders highlighted by hormone and immune alterations in neglected children. This social-health challenge leads to the creation of early stress models such as maternal separation (MS) in rodents. We performed a MS model (4h per day, 21) ( $n=16 \mathrm{MS}$ and $\mathrm{n}=16$ control), and then measured three parameters in male rat adult brains, in order to look for long-term effects: GFAP-positive cells, which indicate astroglial changes, and Iba-1-positive cells, which inform us about reactive microglia and interleukin determination (IL-6, TNF $\alpha$ ). These measurements were performed in prefrontal cortices, striatal areas, and the dorsal hippocampus. We found that MS produces a dramatic and sustained decrease in the astroglial population in all the areas measured, whereas microglial changes are more specific to striatal areas.
\end{abstract}

\author{
Key Words: \\ Early life stress \\ Maternal separation \\ Microglia \\ Astrocytes \\ Iba-1 \\ GFAP
}

Lay summary: A stressful environment in the first stages of life is devastating to brain cells, producing the death of some of them (called astroglial cells), along with an increase in brain inflammation, which is suspected of inducing major depression and other neurological disorders. 


\section{Introduction}

Childhood maltreatment and neglect, suffered by millions of children every year, leads to a wide range of mental disorders (personality, substance abuse, anxiety, depression, suicide, and so on), but it has also been related to physical health problems such as cancer or autoimmune disorders (Karatekin, Almy, Mason, Borowsky, \& Barnes, 2018; Rasmussen, Arefjord, Winje, \& Dovran, 2018; Salokangas et al., 2018). In fact, there is an elevated immune response in neglected children (Delpech et al., 2016).This socialhealth challenge leads to the creation of early stress models such as maternal separation (MS). The repeated lack of contact between mother and litter in rodents, which need maternal care, seems to emulate neurobiological effects of early stress in humans (Jawahar, Murgatroyd, Harrison, \& Baune, 2015; Oreland, Nylander, \& Pickering, 2010; Vetulani, 2013).

Stress (Endocrine system) and inflammation (Immune system) usually work together. Chronic stress periods are followed by inflammation (Gdek-Michalska \& Bugajski, 2010), and after chronic inflammation, microglial cells, which show glucocorticoid receptors, change their shape and become hypertrophied. High and persistent levels of cytokines affect not only microglia, but also astroglial cells (Calcia et al., 2016).

Iba-1, the intracellular ionized calcium-binding adapter protein is present in microglia, and it is upregulated during inflammation (Leinders et al., 2013; Tischer et al., 2016). Glial cells participate in inflammation processes within the nervous system, and chronic cytokine elevations (like TNF $\alpha$ or IL-6) may induce changes in these cells (Calcia et al., 2016). Chronic stress has repeatedly been shown to increase cytokines (Tian, Hou, Li, \& Yuan, 2014), and these elevations are related to depressive symptoms (Peng, Wang, Jiang, \& Wang, 2013) or lead to cellular changes in shape, such as microglial hyperramification or reductions in dendritic spines (Yirmiya, Rimmerman, \& Reshef, 2015).

GFAP is the main cytoskeletal astroglial protein (Barros, Duhalde-Vega, Caltana, Brusco, \& Antonelli, 2006). Some authors have found changes in GFAP during adolescence in early stressed subjects (Marco et al., 2013; Mela et al., 2015), which indicates that stress hormones or immune messengers such as cytokines influence this cell population.

Our aim in this study was to explore whether prolonged and repeated MS leads to immune and glial changes in the brain. This could provide an explanation for the 
behavioral outcomes in this model, such as lack of cognitive flexibility (Banqueri, Méndez, \& Arias, 2018) or the use of alternative brain networks to solve a learning task (Banqueri, Méndez, \& Arias, 2017b). We performed a 21-day MS protocol, and we assessed cytokine levels and microglial, and astroglial counts in adulthood.

\section{Materials and Methods}

\section{Animals}

32 adult Wistar male rats (Rattus norvegicus) were purchased from the animalarium at Oviedo University. All the animals received ad libitum food and tap water and were maintained at a constant room temperature $\left(22+/-2{ }^{\circ} \mathrm{C}\right)$, with a relative humidity of 65 $75 \%$ and a $12 \mathrm{~h}$ artificial light-dark cycle (08:00-20:00/20:00-08:00). The procedures and manipulation of the animals used in this study were carried out according to the Directive (2010/63/EU), Royal Decree 53/2013 of the Ministry of the Presidency, related to the protection of animals used for experimentation and other scientific purposes, and they were approved by the Principality of Asturias committee for animal studies.

\section{Maternal separation}

Litters were randomly assigned to maternal separation or animal facility rearing (AFR) conditions. Litters with more than 10 animals were culled to 10 , with approximately the same number of males and females in each. For MS, litters were separated from the dams for 4 hours per day, starting at 10:00 hours and ending at 14:00 hours. The MS21 group was separated from PND 1 to PND 21. Each separation consisted of removing the dams from the home cage and placing them in an adjacent cage while the pups were kept together in a new cage. Litters remained together during the separation time in an incubator $\left(30^{\circ} \mathrm{C}, 55-65 \%\right.$ relative humidity). After the separation period, the dam and the litter were returned to the home cage (placing the litter in the home cage first). Control litters were reared under standard animal facility rearing (AFR) conditions, disturbed only by animal facility husbandry practices once a week until weaning. On PND 21, all the animals were weaned and segregated by sex, and only males were selected for the study. Therefore, two groups of male animals were included in the experiment, one control group, or AFR $(\mathrm{n}=16)$, and one experimental group: MS21 ( $\mathrm{n}$ $=16)$. 


\section{Sacrifice}

In order to perform immunocytochemistry, we fixed the brains using transcardiac perfusion on PND 100. The animals were administered i.p., a combination of ketamine (Imalgene ${ }^{\circledR}$, Merial) $80 \mathrm{mg} / \mathrm{kg}$, and xilacine (Rompún ${ }^{\circledR}$, Bayer) $10 \mathrm{mg} / \mathrm{kg}$ to achieve deep anesthesia. Once the animal was deeply anesthetized, we accessed the heart. First, we administered $0.1 \mathrm{ml}$ of heparin (Hospira ${ }^{\circledR}$ ) to prevent thrombus. We connected the left ventricle to a vascular perfusion bomb (Ismatec corp. Spain), which infused saline solution $(0.9 \%)$ for 5 minutes, and later paraformaldehyde $4 \%$ in PBS pH 7.4, for 20 minutes. Finally, brains were extracted and sectioned by their longitudinal fissure.

\section{Tissue preparation}

Brains were submerged in paraformaldehyde (4\% in PBS pH 7.4) for 12 hours. Afterwards, they were transferred to PBS with $30 \%$ sucrose $(0.1 \mathrm{M} ; \mathrm{pH} 7.4)$ until they sank, usually $24-48 \mathrm{~h}$. Then, we dehydrated the brains in ethanol at increasing concentrations $\left(70^{\circ}-80^{\circ}-96^{\circ} \mathrm{I}-96^{\circ} \mathrm{II}-100^{\circ} \mathrm{I}-100^{\circ} \mathrm{II}\right)$, for 30 minutes in each. Later, brains were transferred to butyl and, subsequently, introduced into paraffin at $37^{\circ} \mathrm{C}$ for 2 hours and then overnight. The next morning, the brains were paraffin embedded. Brains were sliced, $20 \mu \mathrm{m}$ thick, using a microtome (Leica, RM2135, Germany). We obtained slides for GFAP and Iba-1 immunocytochemistry.

\section{GFAP Immunocytochemistry}

GFAP immunocytochemistry was performed in 8 regions of interest: medial prefrontal areas, mPFC (Cingulate, CG; prelimbic, PL and infralimbic, IL cortices) hippocampal subfields (CA1, CA3, and dentate gyrus: DG) nucleus accumbens (ACC) and dorsal striatum (STD). We performed the method previously described by Blanco et al (Blanco et al., 2006). Briefly, we proceeded to wash the previously deparaffinised sections in Tris buffer saline (TBS) with Triton X-100 at $0.1 \%$ and block them with human serum. Afterwards, these sections were incubated overnight with rabbit polyclonal primary antibody anti GFAP (DAKO 1:800 in bovine albumin, BSA). The next morning, after rinsing in TBS with Triton X-100, we incubated them with a biotinylated secondary antibody (Pierce, goat anti-rabbit IgG, 1:480 in BSA) and applied the avidin- biotin horseradish peroxidase complex (Thermo Fisher Vectastain Ultra-Sensitive ABC Staining Kit), developed with diaminobenzidine tetrahydrochloride, and cover-slipped the sections. 


\section{Iba-1 Immunocytochemistry}

Iba-1 immunocytochemistry was carried out in the same regions of interest: CG, PL IL, CA1, CA3, DG, ACC, and STD. We used a mild modification of the Leinder et al. method (Leinders et al., 2013). We proceeded to wash the previously deparaffinised sections in Tris buffer saline (TBS) with Triton X-100 at $0.1 \%$ and block them with human serum. Afterwards, these sections were incubated overnight with rabbit polyclonal primary antibody anti Iba-1 (Fujifilm Wako chemicals Europe, 1:480 in bovine albumin, BSA). The next morning, after rinsing in TBS with Triton X-100, we incubated them with a biotinylated secondary antibody (Pierce, goat anti-rabbit IgG, 1:30 in BSA) and applied the avidin- biotin horseradish peroxidase complex (Thermo Fisher Vectastain Ultra-Sensitive ABC Staining Kit), developed with diaminobenzidine tetrahydrochloride, and cover-slipped the sections.

\section{Positive cell counting: GFAP \& Iba-1}

Density of GFAP and Iba-1 was quantified in six alternate sections $20 \mu \mathrm{m}$ apart containing the IL, PL, CG, ACC, STD, CA1, CA3, and DG. Coronal sections of these brain regions were located using the rat stereotaxic atlas by Paxinos and Watson (Paxinos \& Watson, 2005). Distance of brain regions in mm counted from bregma was: +3.2 for IL, PL and CG cortex, + 1.20 for ACC and STD, and -3.24 for dorsal hippocampus. Quantification was done by systematically sampling each of the regions selected using counting frames superimposed over the region $\left(500 \mathrm{X} 500 \mu \mathrm{m}^{2}\right)$. Cell counts were conducted using a microscope (Leica DFC490, Germany) coupled to a computer with software (Leica application suite, Germany). Each GFAP or Iba- 1 positive cell was counted only if the cell body was focused within each quadrant or dissector. The total thickness measured on each slide was $10 \mu \mathrm{m}$, leaving out $5 \mu \mathrm{m}$ of thickness above and below the Z-axis to avoid possible overestimations. Finally, the mean count of six sections (12 counting frames per area, 6 animals per group) was calculated for each subject and region.

\section{Interleukins determination: Real time RT-PCR measurement of mRNA expression,}

\section{IL-6 and TNFa}

Eight animals per group (8 AFR and 8 MS21) were decapitated on PND 100. Brains were removed, and the whole striatum, hippocampus, and prefrontal cortex were dissected. All dissections were performed under sterile conditions. The samples were 
frozen rapidly in N-methyl butane (Sigma-Aldrich, Madrid, Spain) and stored at $-80{ }^{\circ} \mathrm{C}$ to measure mRNA expression of IL- 6 and TNF- $\alpha$ in the prefrontal cortex, hippocampus, and striatum. Brain tissue was homogenized using the trizol reagent (Invitrogen, Madrid, Spain), and total RNA was isolated utilizing a standard method of phenol : chloroform extraction (Chomczyński \& Sacchi, 1987). A UV spectrophotometric analysis of nucleic acid was performed at $260 \mathrm{~nm}$ to determine RNA concentrations, and the 260:280 absorption ratio was utilized to assess nucleic acid purity. Samples were DNase-treated (DNase I, Invitrogen, Madrid, Spain) to remove contaminating DNA prior to cDNA synthesis. The total RNA was then reverse- transcribed using the PrimeScript ${ }^{\mathrm{TM}}$ RT reagent kit (Takara Bio Inc., Madrid, Spain), and resulting cDNA levels were quantified by SybrGreen-based (SYBR ${ }^{\circledR}$ Premix Ex Taq ${ }^{\mathrm{TM}}$ Takara Bio Inc., Madrid, Spain) real time PCR. Formation of PCR products was monitored in real time using the Applied Biosystems 7500 Real Time PCR System. The sequences of cDNA were obtained from Gen Bank at the National Center for Biotechnology Information (NCBI; www.ncbi.nlm.nih. gov). Glyceraldehyde-6-phosphate dehydrogenase (GAPDH) served as a housekeeping gene. Primer sequences were designed using the Primer Express Software v3.0 (Applied Biosystems). Primers were obtained from Applied Biosystems (Madrid, Spain). Prime specificity was verified by melt curve analysis. Relative gene expression was determined using the $2-\Delta \Delta t$ method (Livak \& Schmittgen, 2001). Primer sequences used for PCR were as follows (primer sequence direction is $5^{\prime} \ldots 3^{\prime}$ ): IL-6, forward: CCACCAGGAA CGAAAGTCAAC, reverse: CTTGCGGAGAGAAACTTCATAGC; TNF- $\alpha$, forward: GCCACCGGCAAGGATTC, reverse: TCGACATTCCGGGATC CA.

\section{Statistical Analysis}

The data recorded were analyzed using the SigmaStat software version 3.2 (Systat, Richmond, USA). In all cases, significance was accepted when $p<0.050$. Mauchly's test was used to test the sphericity assumption in repeated-measures analysis. Because the data met the sphericity assumption, uncorrected $\mathrm{F}$ tests were presented.

\section{Inmunohistochemistry: GFAP and Iba-1}

Six subjects were analyzed per group. Cell counts from the six selected sections of a given brain region in each animal were averaged, and the mean was used for statistical analysis. One-way ANOVA was used to assess whether the number of Iba-1 or GFAP 
positive was different between groups. When the ANOVA detected significant differences, Tukey post hoc tests were used to clarify differences between individual groups.

\section{Real time RT-PCR measurement of mRNA expression: TNFa and IL-6}

Eight subjects were analyzed per group. 3 areas were tested: Dorsal striatum, hippocampus, and prefrontal cortex. Relative expression of both cytokines was averaged per group and area. One-way ANOVA was used, and when significant differences were detected, Tukey post hoc tests were used to clarify differences between groups.

\section{Results}

\section{Iba-1}

Iba-1 positive cells per area were measured and averaged per subject and group. The MS21 group showed more Iba-1 positive cells in striatal areas: ACC: $F_{(1,11)}=5,224$, $p=0.045$, STD: $\mathrm{F}_{(1,11)}=7,235, \mathrm{p}=0.023$; and CA3 $F_{(1,11)}=6,254, p=0.031$. There were no differences between groups on the rest of the hippocampal areas: CA1: $F_{(1,11)}=$ 0,143, $p=0.713$; DG: $F_{(1,11)}=3,102, p=0.109$ or medial prefrontal cortices: IL: $F_{(1,11)}=$ 1,310, $p=0.279$; PL: $F_{(1,11)}=0,696, p=0.424 ; \mathrm{CG}: F_{(1,11)}=0.489, p=0.500$ (Figure 1).

\section{GFAP}

GFAP positive cells per area were measured and averaged per subject and group. The MS21 group showed fewer GFAP positive cells in striatal: ACC: $H_{1}=8,337, p=0.002$; STD: $H_{1}=8,308, p=0.002$; hipocampal, CA1: $H_{1}=5,026, p=0.026$, CA3: $F_{(1,11)}=$ 123,020, $p<0.001, \mathrm{DG}: F_{(1,11)}=7,766, p=0.019$, and medial prefrontal areas: PL; $H_{1}=$ $7,410, p=0.004$ and $\mathrm{CG} ; \mathrm{F}_{(1,11)}=33,508, p<0.001$. IL showed no significant differences $\left(F_{(1,11)}=4,648, p=0.056\right)$ (Figure 2).

\section{$I L-6 \& T N F \alpha$}

Relative expression of IL-6 RNA was greater in the MS21 hippocampus HC: $F_{(1,16)}=$ $5,974, p=0.027$, but MS had no effect on its levels in PFC $F_{(1,16)}=0,0357, p=0.853$, either in $\operatorname{STD} F_{(1,16)}=0,107, p=0.748$. Relative expression of TNF $\alpha$ RNA was equal in both groups at the PFC: $F_{(1,16)}=0,865, p=0.367$, $\operatorname{STD}\left(F_{(1,16)}=2,796, p=0.115\right)$ and HC $\left(F_{(1,16)}=0,0125, p=0.912\right)$ levels (Figure 3$)$. 


\section{Discussion}

Microglia are immune resident cells of the brain. They are very sensitive to environmental changes, and they regulate neuronal communication (Delpech et al., 2016; Ganguly, Thompson, Gildawie, \& Brenhouse, 2018). Microglia originate from myeloid precursor cells from the yolk sac that migrate to the nervous central system. These immune cells are regulators of normal and pathological brain development (Lenz $\&$ Nelson, 2018). During the perinatal period, there is a dense microglial proliferation and activity (Hanamsagar \& Bilbo, 2017), which makes this early stage sensitive to environmental challenges. Microglia display many functions; they phagocytize apoptotic cells, and support neurogenesis and neuronal wiring (Hanamsagar \& Bilbo, 2017; Lenz \& Nelson, 2018; Tay et al., 2018).

As mentioned in the introduction, Iba-1, the intracellular ionized calcium-binding adapter protein, is present in microglia. This protein participates in membrane ruffling essential to morphologic cell changes from quiescent to activated microglia (Réus et al., 2018). The rationale is that the more Iba-1, the more active microglia there are in the studied areas. We found that the MS21 group showed more Iba-1 positive cells in striatal areas (STD \& ACC) and one hippocampal field (CA3), similarly to other authors (Roque, Ochoa-Zarzosa, \& Torner, 2016). However, there were no differences between groups in the rest of the hippocampal (CA1, DG) areas or PFC (CG, PL, IL). Nonetheless, other authors found an increase in Iba-1 in the PFC (Ganguly et al., 2018), which could be explained by their use of a different stressor (food restriction) and a different point of development (adolescence). These data show that microglial activation does not respond equally to all stressful stimuli.

Microglia respond to stress hormones (Lenz \& Nelson, 2018), and so a chronic stress situation such as MS can cause a microglial response and possibly lead to other changes, such as more motility (Takatsuru, Nabekura, Ishikawa, Kohsaka, \& Koibuchi, 2015) and de-ramification (Tay et al., 2018).

Here, we demonstrate that MS has long-term consequences on microglial activity. Other authors have already shown that early stress induces short-term increases in microglia, on PND 14 and 28 (Delpech et al., 2016), and also mid-term effects (PND 30) (Réus et al., 2018). Several stressors increase microglia markers such as Iba-1, which could be seen as a priming process for these cells that would induce an increased response to 
subsequent insults in later life (Ganguly et al., 2018). When microglial cells are primed in early stages, they could show an exaggerated response in later life, as well as morphological changes (Tay et al., 2018). Therefore we could say that early stress changes the neuroimmune axis to a proinflammatory state (Roque et al., 2016). An increase in microglia makes the brain mature faster, which is a recurrent idea in the early stress bibliography (Richardson, Cowan, Callaghan, \& Kan, 2016). The opposite effect, a temporary depletion of microglia during the postnatal period, leads to a decrease in anxiety-like behavior (Lenz \& Nelson, 2018). Perhaps the anxiety found in early stressed animals (Banqueri et al., 2017a) is related to an early increase in microglia.

When an immune challenge is taking place, cells other than microglia are activated. These glial cells are astrocytes that act under microglial control (Tay et al., 2018), and interestingly, astrocytes can also control microglial activity toward cytokines (Lenz \& Nelson, 2018). Astrocytes are the most numerous subtype of glial cells (Nakamoto, Aizawa, Kinoshita, Koyama, \& Tokuyama, 2017). They are key regulators of the proliferation, differentiation, and survival of new cells, and they also provide support for neurons and control adaptive actions such as inflammatory responses (JaureguiHuerta et al., 2015).

GFAP is a cytoskeletal protein expressed by astrocytes, with structure and movement functions, but it is also related to neuron-astrocyte communication. An increase in GFAP levels indicates an astrocyte activation (Réus et al., 2018). We found fewer GFAP positive cells in striatal (STD \& ACC), Hippocampal (DG, CA3,CA1), and PFC areas (PL \& CG), but IL after MS, similarly to other studies (Réus et al., 2018). Along these lines, some authors claim that glial development is underdeveloped in adults who were submitted to early stress, and the same structures we measured were the most affected (Aguirre-Benítez et al., 2017; Jauregui-Huerta et al., 2015). Focusing on the PFC results, it has been stated that there are fewer astrocytes in the PFC of chronically stressed subjects with their neuronal count unchanged (Baudin et al., 2012; Chocyk, Przyborowska, et al., 2011; Jauregui-Huerta et al., 2015).

The peak of gliogenesis occurs in the second postnatal week (Chocyk, Dudys, et al., 2011); hence, a stress insult like MS could potentially affect this process. Here, we demonstrate a long-term reduction in GFAP-positive cells produced by MS. Other studies have shown short-term effects, finding a GFAP reduction on PND 15 in the PFC 
(Chocyk, Dudys, et al., 2011) and, as a mid-term consequence: GFAP increases in the HC during adolescence in early stressed subjects (Marco et al., 2013; Mela et al., 2015). GFAP is decreased in different brain regions in subjects with mood disorders (Nakamoto et al., 2017) and patients with depression (Réus et al., 2018), and in postmortem studies of depressed subjects (Roque et al., 2016).

As we mentioned above, these glial populations can communicate with immune factors such as cytokines. Stress activates microglia, making these cells release TNF $\alpha$ in the HC but not in the cortex or striatal areas (Ohgidani et al., 2016). We found that relative expression of IL-6 RNA was greater in the MS21 HC, but MS had no effect on its levels in striatal areas (STD) or the PFC. Relative expression of TNF $\alpha$ RNA was equal in the two groups. Other authors found that MS increased TNF- $\alpha$, but in other areas such as the hypothalamus (Roque et al., 2016). MS has been associated with greater synaptic levels of some interleukins like IL-1 (Ganguly et al., 2018), and the same thing is observed in adults who were neglected in their childhood (Gong et al., 2018). There is no difference in IL-6 in the HC of MS pups; however, basal TNF $\alpha$ is increased (Roque et al., 2016). We found a long-term effect of an increase in IL-6 in the HC. Psychological stress has programming effects, setting some immune and hormonal parameters at pathologic levels (Veru, Laplante, Luheshi, \& King, 2014). Although an interleukin increase is expected just after early stress takes place, or after an acute insult, the cellular effects we found show long-term effects of early stress programming.

\section{Conclusions}

In conclusion, we found a more intense long-term effect of MS on astroglia (a decrease in almost all the measured areas) than on microglia, which shows a more specific inflammatory response. This response is mainly found in striatal areas like the accumbens, which belongs to the mesolimbic memory system, and its role is to select behaviorally relevant actions in a given context. The inflammation found in this area could be one of the keys to learning alterations in MS models. Future research is required in order to explore the pathways through which chronic stress becomes cellular loss, in order to prevent these harmful changes or reverse them. 


\section{Acknowledgements}

This research was supported by Projects Grants of the MINECO (Ministerio de Economía y competitividad del Gobierno de España) PSI2017-90806-REDT, PSI201783893-R, PSI 2015-73111-EXP, BES-2014- 070562 to M.B.L.

\section{Disclosure of interest}

The authors report no conflicts of interest.

Word count: 5312

\section{References}

Adamsky, A., Kol, A., Kreisel, T., Doron, A., Ozeri-Engelhard, N., Melcer, T., ... Goshen, I. (2018). Astrocytic Activation Generates De Novo Neuronal Potentiation and Memory Enhancement. Cell, 174(1), 59-71.e14. http://doi.org/10.1016/j.cell.2018.05.002

Aguirre-Benítez, E. L., Porras, M. G., Parra, L., González-Ríos, J., Garduño-Torres, D. F., Albores-García, D., ... Hernández-Falcón, J. (2017). Disruption of behavior and brain metabolism in artificially reared rats. Developmental Neurobiology, 77(12), 1413-1429. http://doi.org/10.1002/dneu.22548

Banqueri, M., Méndez, M., \& Arias, J. L. (2017a). Behavioral effects in adolescence and early adulthood in two length models of maternal separation in male rats. Behavioural Brain Research, 324, 77-86. http://doi.org/10.1016/j.bbr.2017.02.006

Banqueri, M., Méndez, M., \& Arias, J. L. (2017b). Spatial memory-related brain activity in normally reared and different maternal separation models in rats. Physiology \& Behavior, 181(May), 80-85. http://doi.org/10.1016/j.physbeh.2017.09.007

Banqueri, M., Méndez, M., \& Arias, J. L. (2018). Why are maternally separated females inflexible? Brain activity pattern of COx and c-Fos. Neurobiology of Learning and Memory. http://doi.org/10.1016/j.nlm.2018.06.007

Barros, V. G., Duhalde-Vega, M., Caltana, L., Brusco, A., \& Antonelli, M. C. (2006). Astrocyte-Neuron Vulnerability to Prenatal Stress in the Adult Rat Brain Virginia. Journal of Neuroscience Research, 83, 787-800. http://doi.org/10.1002/jn 
Baudin, A., Blot, K., Verney, C., Estevez, L., Santamaria, J., Gressens, P., ... Naudon, L. (2012). Maternal deprivation induces deficits in temporal memory and cognitive flexibility and exaggerates synaptic plasticity in the rat medial prefrontal cortex. Neurobiology of Learning and Memory, 98(3), 207-214. http://doi.org/10.1016/j.nlm.2012.08.004

Blanco, E., Picón, I. M., Miranda, R., Begega, A., Conejo, N. M., \& Arias, J. L. (2006). Astroglial distribution and sexual differences in neural metabolism in mammillary bodies. Neuroscience Letters, 395(1), 82-86. http://doi.org/10.1016/j.neulet.2005.10.061

Calcia, M. A., Bonsall, D. R., Bloomfield, P. S., Selvaraj, S., Barichello, T., \& Howes, O. D. (2016). Stress and neuroinflammation: A systematic review of the effects of stress on microglia and the implications for mental illness. Psychopharmacology, 233(9), 1637-1650. http://doi.org/10.1007/s00213-016-4218-9

Chocyk, A., Dudys, D., Przyborowska, A., Majcher, I., Maćkowiak, M., \& Weogonekdzony, K. (2011). Maternal separation affects the number, proliferation and apoptosis of glia cells in the substantia nigra and ventral tegmental area of juvenile rats. Neuroscience, 173, 1-18.

http://doi.org/10.1016/j.neuroscience.2010.11.037

Chocyk, A., Przyborowska, A., Dudys, D., Majcher, I., Maćkowiak, M., \& Wedzony, K. (2011). The impact of maternal separation on the number of tyrosine hydroxylase-expressing midbrain neurons during different stages of ontogenesis. Neuroscience, 182, 43-61. http://doi.org/10.1016/j.neuroscience.2011.03.008

Chomczyński, P., \& Sacchi, N. (1987). Single-step method of RNA isolation by acid guanidinum thiocyanate-phenol-chlotoform extraction. Analytical Biochemistry, 162(1), 156-159.

Del Ferraro, G., Moreno, A., Min, B., Morone, F., Pérez-Ramírez, Ú., Pérez-Cervera, L., ... Makse, H. A. (2018). Finding influential nodes for integration in brain networks using optimal percolation theory. Nature Communications, 9(1). http://doi.org/10.1038/s41467-018-04718-3

Delpech, J.-C., Wei, L., Hao, J., Xiaoqing, Y., Madore, C., Butovsky, O., \& Kaffman, A. (2016). Early life stress perturbs the maturation of microglia in the developing 
hippocampus. Brain, Behavior and Immunity, 57, 79-93.

http://doi.org/10.1158/1541-7786.MCR-15-0224.Loss

Ganguly, P., Thompson, V., Gildawie, K., \& Brenhouse, H. C. (2018). Adolescent food restriction in rats alters prefrontal cortex microglia in an experience-dependent manner. Stress, 4(11), 162-168. http://doi.org/10.1016/S2214-109X(16)302650. Cost-effectiveness

Gdek-Michalska, A., \& Bugajski, J. (2010). Interleukin-1 (IL-1) in stress-induced activation of limbic-hypothalamic-pituitary adrenal axis. Pharmacological Reports, 969-982.

Gong, Y., Tong, L., Yang, R., Hu, W., Xu, X., Wang, W., ... Huang, C. (2018). Dynamic changes in hippocampal microglia contribute to depressive-like behavior induced by early social isolation. Neuropharmacology, 135, 223-233. http://doi.org/10.1016/j.neuropharm.2018.03.023

Gracia-Rubio, I., Moscoso-Castro, M., Pozo, O. J., Marcos, J., Nadal, R., \& Valverde, O. (2016). Maternal separation induces neuroinflammation and long-lasting emotional alterations in mice. Progress in Neuro-Psychopharmacology and Biological Psychiatry, 65, 104-117. http://doi.org/10.1016/j.pnpbp.2015.09.003

Hanamsagar, R., \& Bilbo, S. D. (2017). Environment matters: microglia function and dysfunction in a changing world. Current Opinion in Neurobiology, 47, 146-155. http://doi.org/10.1016/j.conb.2017.10.007

Jauregui-Huerta, F., Zhang, L., Yañez-Delgadillo, G., Hernandez-Carrillo, P., GarcíaEstrada, J., \& Luquín, S. (2015). Hippocampal cytogenesis and spatial learning in senile rats exposed to chronic variable stress: Effects of previous early life exposure to mild stress. Frontiers in Aging Neuroscience, 7(JUL), 1-10. http://doi.org/10.3389/fnagi.2015.00159

Jawahar, M. C., Murgatroyd, C., Harrison, E. L., \& Baune, B. T. (2015). Epigenetic alterations following early postnatal stress: A review on novel aetiological mechanisms of common psychiatric disorders. Clinical Epigenetics. http://doi.org/10.1186/s13148-015-0156-3

Karatekin, C., Almy, B., Mason, S. M., Borowsky, I., \& Barnes, A. (2018). Mental and Physical Health Profiles of Maltreated Youth. Child Abuse \& Neglect, 84(April), 
23-33. http://doi.org/10.1016/j.chiabu.2018.07.019

Leinders, M., Knaepen, L., De Kock, M., Sommer, C., Hermans, E., \& Deumens, R. (2013). Up-regulation of spinal microglial Iba-1 expression persists after resolution of neuropathic pain hypersensitivity. Neuroscience Letters, 554, 146-150. http://doi.org/10.1016/j.neulet.2013.08.062

Lenz, K. M., \& Nelson, L. H. (2018). Microglia and beyond: Innate immune cells as regulators of brain development and behavioral function. Frontiers in Immunology, 9(APR). http://doi.org/10.3389/fimmu.2018.00698

Livak, K. J., \& Schmittgen, T. D. (2001). Analysis of relative gene expression data using real-time quantitative PCR and the 2(-Delta Delta C(T)) Method. Methods (San Diego, Calif.). http://doi.org/10.1006/meth.2001.1262

Marco, E. M., Valero, M., De La Serna, O., Aisa, B., Borcel, E., Ramirez, M. J., \& Viveros, M. P. (2013). Maternal deprivation effects on brain plasticity and recognition memory in adolescent male and female rats. Neuropharmacology, 68, 223-231. http://doi.org/10.1016/j.neuropharm.2012.08.014

Mela, V., Díaz, F., Borcel, E., Argente, J., Chowen, J. A., \& Viveros, M. P. (2015). Long term hippocampal and cortical changes induced by maternal deprivation and neonatal Leptin treatment in male and female rats. PLoS ONE, 10(9), 1-25. http://doi.org/10.1371/journal.pone.0137283

Nakamoto, K., Aizawa, F., Kinoshita, M., Koyama, Y., \& Tokuyama, S. (2017). Astrocyte activation in locus coeruleus is involved in neuropathic pain exacerbation mediated by maternal separation and social isolation stress. Frontiers in Pharmacology, 8(JUN), 1-10. http://doi.org/10.3389/fphar.2017.00401

Ohgidani, M., Kato, T. A., Sagata, N., Hayakawa, K., Shimokawa, N., Sato-Kasai, M., \& Kanba, S. (2016). TNF- $\alpha$ from hippocampal microglia induces working memory deficits by acute stress in mice. Brain, Behavior, and Immunity, 55, 17-24. http://doi.org/10.1016/j.bbi.2015.08.022

Oreland, S., Nylander, I., \& Pickering, C. (2010). Prolonged maternal separation decreases granule cell number in the dentate gyrus of 3-week-old male rats. International Journal of Developmental Neuroscience, 28(2), 139-144. http://doi.org/10.1016/j.ijdevneu.2009.12.005 
Peng, Y.-L., Wang, W.-Y., Jiang, C.-L., \& Wang, Y.-X. (2013). Roles of cytokines in stress-induced depression. Acta Physiologica Sinica, 65(2), 229-36. Retrieved from http://www.ncbi.nlm.nih.gov/pubmed/23598881

Rasmussen, I. S., Arefjord, K., Winje, D., \& Dovran, A. (2018). Childhood maltreatment trauma: a comparison between patients in treatment for substance use disorders and patients in mental health treatment. European Journal of Psychotraumatology, 9(1), 1492835. http://doi.org/10.1080/20008198.2018.1492835

Réus, G. Z., Silva, R. H., de Moura, A. B., Presa, J. F., Abelaira, H. M., Abatti, M., ... Quevedo, J. (2018). Early Maternal Deprivation Induces Microglial Activation, Alters Glial Fibrillary Acidic Protein Immunoreactivity and Indoleamine 2,3Dioxygenase during the Development of Offspring Rats. Molecular Neurobiology, 1-13. http://doi.org/10.1007/s12035-018-1161-2

Richardson, R., Cowan, C. S. M., Callaghan, B. L., \& Kan, J. M. (2016). Effects of early-life stress on fear memory in the developing rat. Current Opinion in Behavioral Sciences, 7, 15-20. http://doi.org/10.1016/j.cobeha.2015.10.003

Roque, A., Ochoa-Zarzosa, A., \& Torner, L. (2016). Maternal separation activates microglial cells and induces an inflammatory response in the hippocampus of male rat pups, independently of hypothalamic and peripheral cytokine levels. Brain, Behavior, and Immunity, 55, 39-48. http://doi.org/10.1016/j.bbi.2015.09.017

Salokangas, R. K. R., Patterson, P., Hietala, J., Heinimaa, M., From, T., Ilonen, T., ... Ruhrmann, S. (2018). Childhood adversity predicts persistence of suicidal thoughts differently in females and males at clinical high-risk patients of psychosis. Results of the EPOS project. Early Intervention in Psychiatry, 1-8. http://doi.org/10.1111/eip.12714

Stamatakis, A., Manatos, V., Kalpachidou, T., \& Stylianopoulou, F. (2016). Exposure to a mildly aversive early life experience leads to prefrontal cortex deficits in the rat. Brain Structure and Function, 221(8), 4141-4157. http://doi.org/10.1007/s00429015-1154-0

Takatsuru, Y., Nabekura, J., Ishikawa, T., Kohsaka, S. ichi, \& Koibuchi, N. (2015). Early-life stress increases the motility of microglia in adulthood. Journal of 
Physiological Sciences, 65(2), 187-194. http://doi.org/10.1007/s12576-015-0361-z

Tay, T. L., Béchade, C., D’Andrea, I., St-Pierre, M.-K., Henry, M. S., Roumier, A., \& Tremblay, M.-E. (2018). Microglia Gone Rogue: Impacts on Psychiatric Disorders across the Lifespan. Frontiers in Molecular Neuroscience, 10(January), 1-26. http://doi.org/10.3389/fnmol.2017.00421

Tian, R., Hou, G., Li, D., \& Yuan, T. F. (2014). A possible change process of inflammatory cytokines in the prolonged chronic stress and its ultimate implications for health. Scientific World Journal, 2014. http://doi.org/10.1155/2014/780616

Tischer, J., Krueger, M., Mueller, W., Staszewski, O., Prinz, M., Streit, W. J., \& Bechmann, I. (2016). Inhomogeneous distribution of Iba-1 characterizes microglial pathology in Alzheimer's disease. Glia, 64(9), 1562-1572. http://doi.org/10.1002/glia.23024

Veru, F., Laplante, D. P., Luheshi, G., \& King, S. (2014). Prenatal maternal stress exposure and immune function in the offspring. Stress, 17(2), 133-148. http://doi.org/10.3109/10253890.2013.876404

Vetulani, J. (2013). Early maternal separation: a rodent model of depression and a prevailing human condition. Pharmacological Reports : PR, 65(6), 1451-61. http://doi.org/10.1016/S1734-1140(13)71505-6

Wei, L., Hao, J., Lacher, R. K., Abbott, T., Chung, L., Colangelo, C. M., \& Kaffman, A. (2015). Early-life stress perturbs key cellular programs in the developing mouse hippocampus. Developmental Neuroscience. http://doi.org/10.1159/000430861

Yirmiya, R., Rimmerman, N., \& Reshef, R. (2015). Depression as a Microglial Disease. Trends in Neurosciences, 38(10), 637-658. http://doi.org/10.1016/j.tins.2015.08.001 


\section{Figures}

\section{Figure 1}

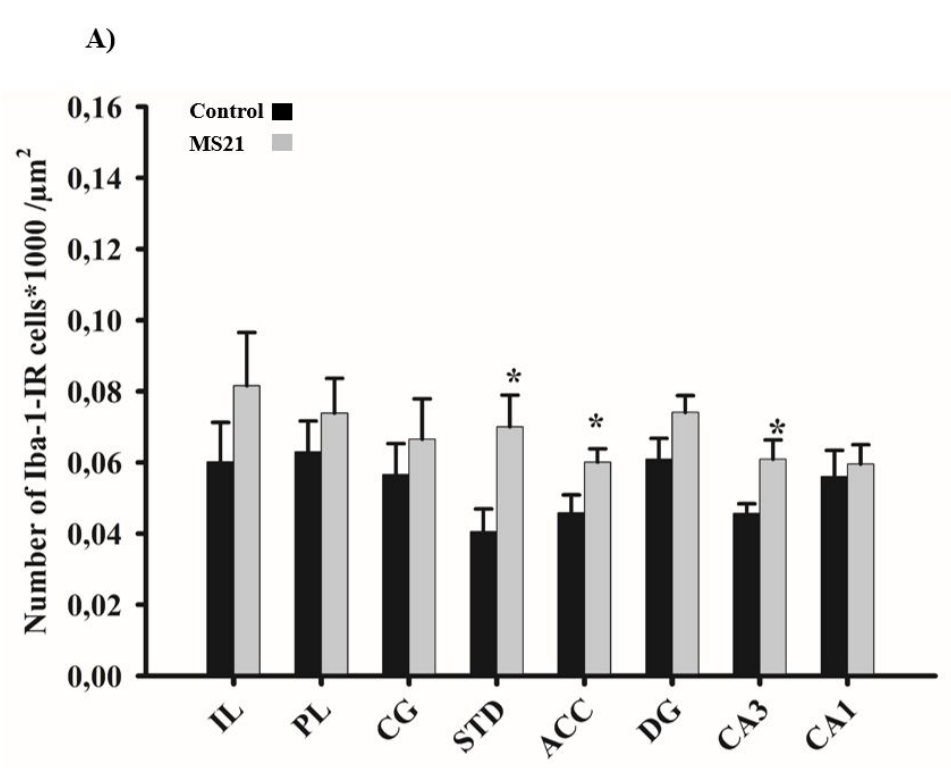

B)

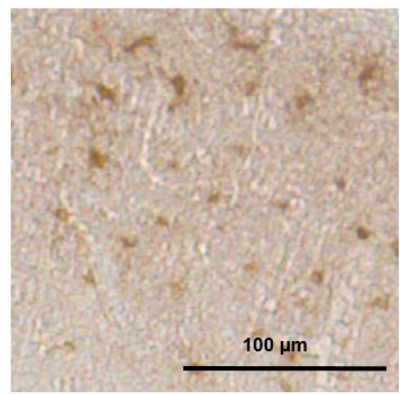

C)

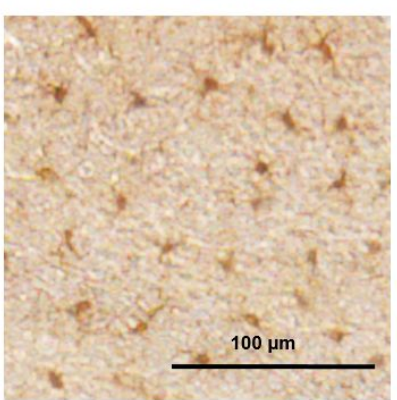

Figure 2

A)

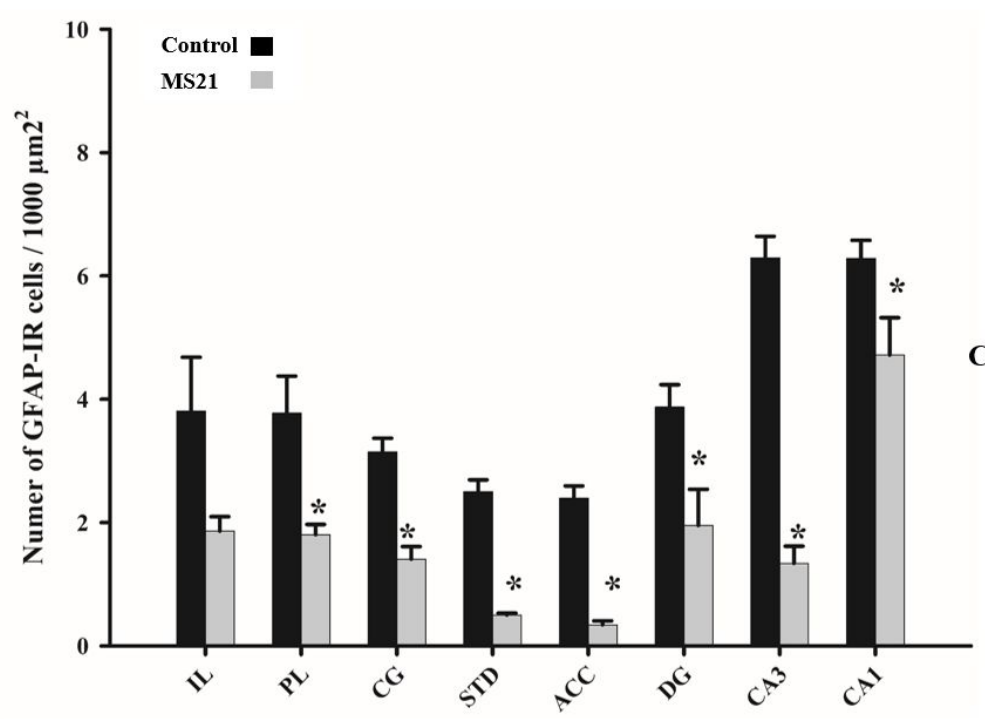

B)

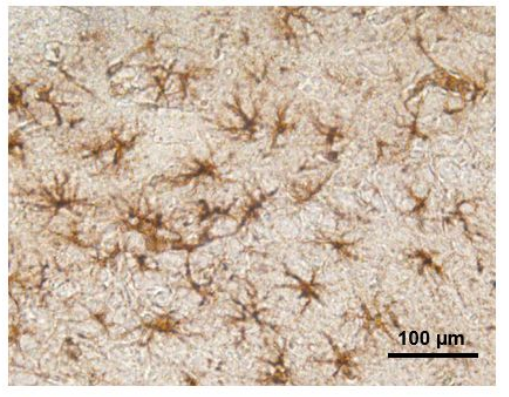

C)

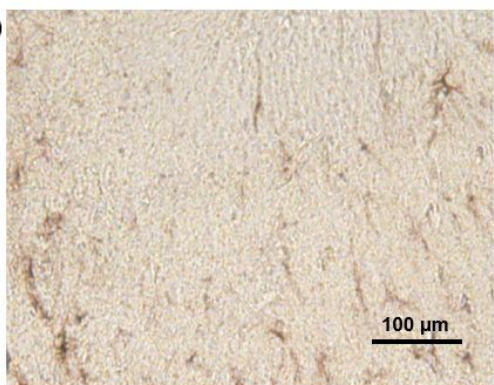




\section{Figure 3}

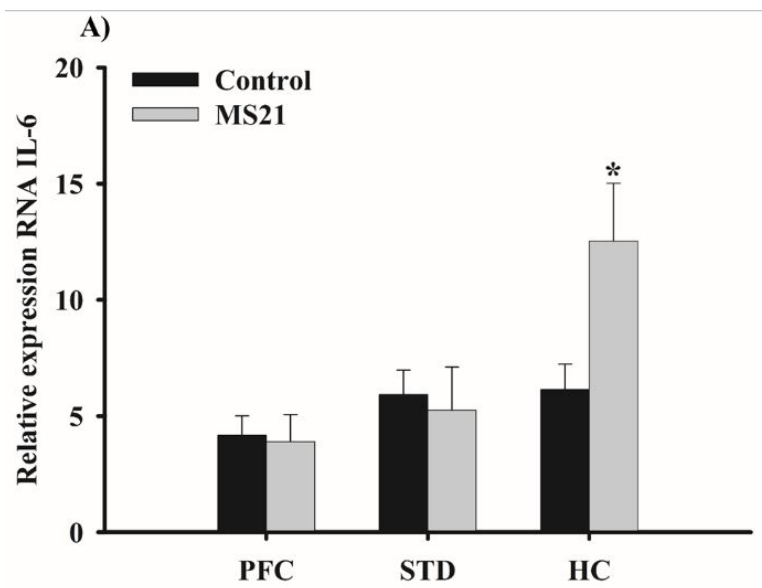

B)

\section{Captions}

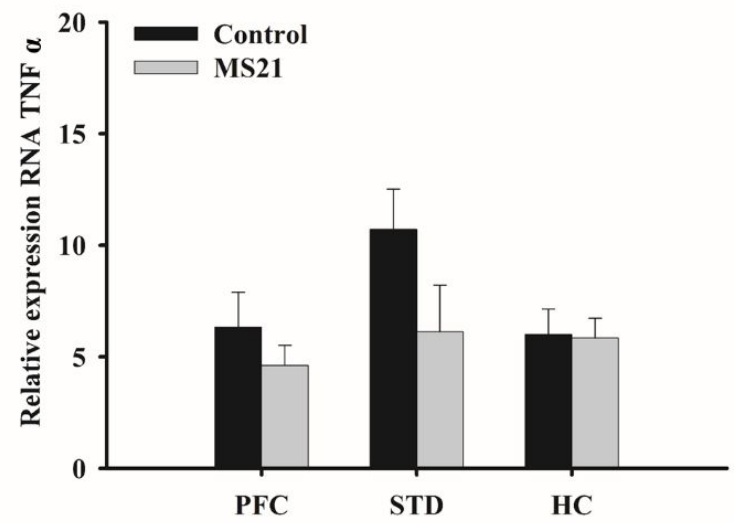

Figure 1: A) Results of Iba-1R cells $/ \mu \mathrm{m}^{2} \cdot p>0.05$. B) Representative microphotograph of the Iba-1 immunohistochemistry in STD of one subject from control group. C) Representative microphotograph of the Iba-1 immunohistochemistry in STD of one subject from MS21 group. Cingulate, CG; prelimbic, PL; and infralimbic, IL; dentate gyrus, DG; nucleus accumbens ACC; dorsal striatum, STD.

Figure 2: A) Results of GFAP-R cells $/ \mu \mathrm{m}^{2} \cdot p>0.05$. B) Representative microphotograph of the GFAP immunohistochemistry in DG of one subject from control group. C) Representative microphotograph of the GFAP immunohistochemistry in DG of one subject from MS21 group. Cingulate, CG; prelimbic, PL; and infralimbic, IL; dentate gyrus, DG; nucleus accumbens ACC; dorsal striatum, STD.

Figure 3: Relative expression of IL-6 RNA in control and MS21 groups (left) and relative expression of TNF $\alpha$ RNA in control and MS21 groups (right) $p>0.05$, obtained by RT-PCR. 

A)

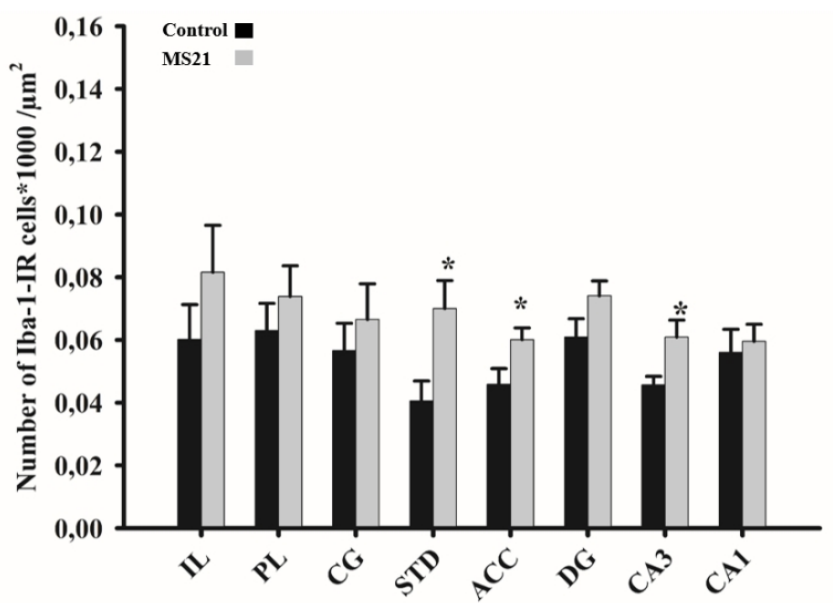

B)

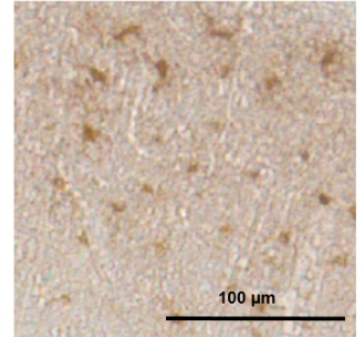

C)

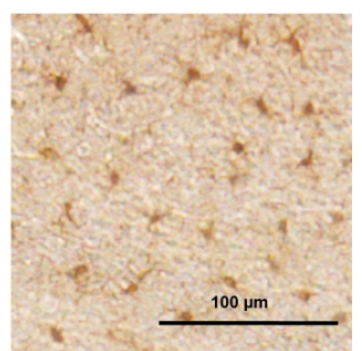

Figure 1: A) Results of Iba-1R cells/ $\mu$ m2. p>0.05. B) Representative microphotograph of the Iba-1 immunohistochemistry in STD of one subject from control group. C) Representative microphotograph of the Iba-1 immunohistochemistry in STD of one subject from MS21 group. Cingulate, CG; prelimbic, PL; and infralimbic, IL; dentate gyrus, DG; nucleus accumbens ACC; dorsal striatum, STD.

$446 \times 250 \mathrm{~mm}(72 \times 72 \mathrm{DPI})$ 
A)

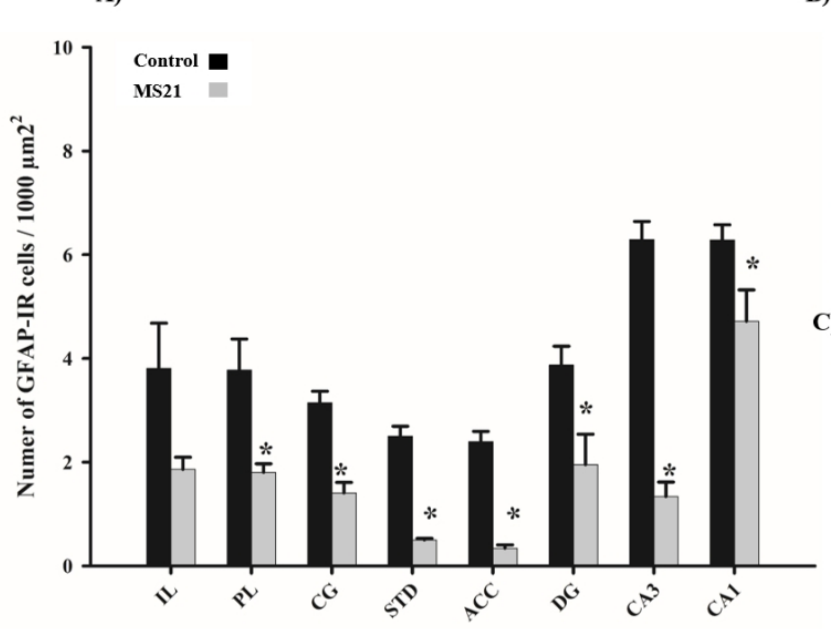

B)
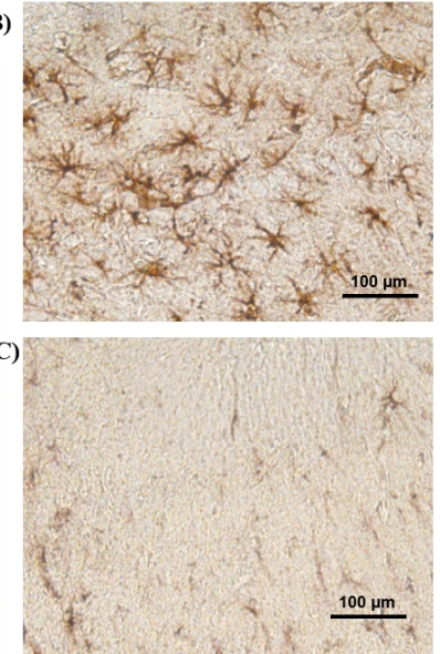

Figure 2: A) Results of GFAP-R cells/ $\mu \mathrm{m} 2$. $\mathrm{p}>0.05$. B) Representative microphotograph of the GFAP immunohistochemistry in DG of one subject from control group. C) Representative microphotograph of the GFAP immunohistochemistry in DG of one subject from MS21 group. Cingulate, CG; prelimbic, PL; and infralimbic, IL; dentate gyrus, DG; nucleus accumbens ACC; dorsal striatum, STD.

$$
452 \times 238 \mathrm{~mm}(72 \times 72 \mathrm{DPI})
$$



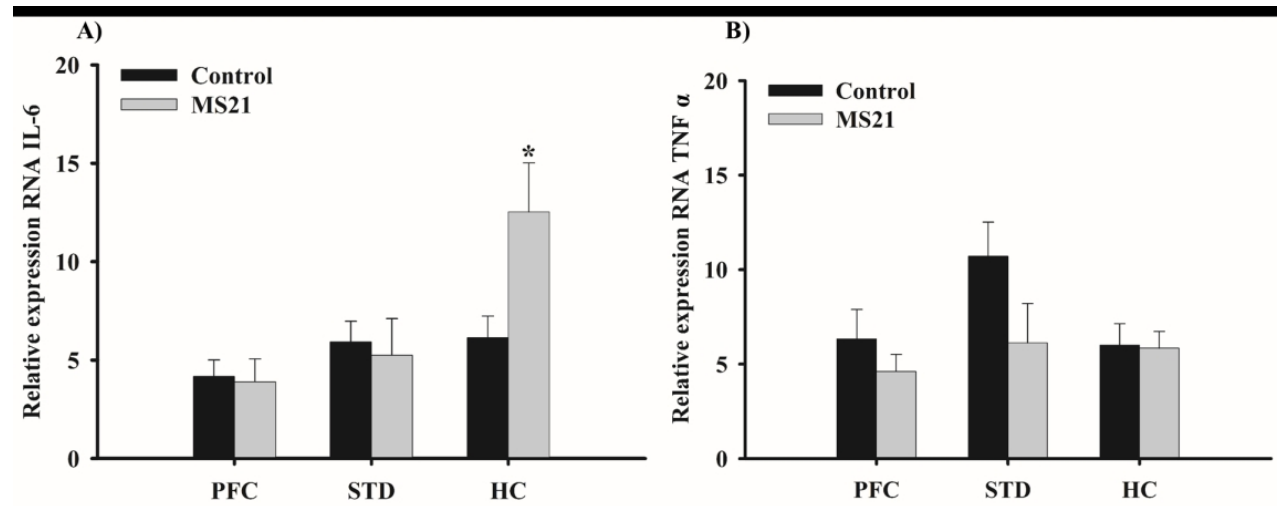

Figure 3: Relative expression of IL-6 RNA in control and MS21 groups (left) and relative expression of TNFa RNA in control and MS21 groups (right) p>0.05, obtained by RT-PCR.

$673 \times 274 \mathrm{~mm}(72 \times 72 \mathrm{DPI})$ 